\title{
RECORDING AND ANALYSIS OF THE REC YARD AT ALCATRAZ ISLAND
}

\author{
R. Warden ${ }^{\mathrm{a}, *}$, T.Komas. Toz ${ }^{\mathrm{b}}$, M. Everett ${ }^{\mathrm{a}}$, T. DeSmet $^{\mathrm{a}}$, A.Billingsley, ${ }^{\mathrm{a}} \mathrm{J}_{\text {H.Hagin }}{ }^{\mathrm{c}}$
}

${ }^{\text {a }}$ Texas A\&M University, Dept. of Architecture, TAMU 3137 College Station, TX, r-warden@tamu.edu

${ }^{\mathrm{b}}$ California State University, Chico, Concrete Industry Management Program, College of Engineering, California State University, Chico | Chico, CA 95929-0003 Program Office: 530.898.5963Street. tomas@ csuchico.edu

c Golden Gate National Recreation Area,201 Fort Mason, San Francisco, CA 94123, Jason_hagin@nps.gov

KEY WORDS: Laser Scanning, Photogrammetry, GPR, Preservation, Non-destructive Testing

\section{ABSTRACT:}

In the summer of 2012 students and professors from the Concrete Industry Management (CIM ) program at California State University Chico, along with their partners at National Park Service, invited Texas A\&M students and professors to join forces and perform a condition assessment of the Recreation Yard at Alcatraz Island in San Francisco Bay. The Recreation Yard is a heavily visited area by tourists who are drawn to the island because of its history as a maximum security prison in the $20^{\text {th }} \mathrm{c}$. Because of its history, first as a military fort in the $19^{\text {th }} \mathrm{c}$., later as a military prison, and finally as a federal prison, many difficult historical and preservation related questions exist. This team was formed to begin research on the historical and preservation questions with respect to the Recreation Yard.

This paper and presentation will focus on the integration of documentation technologies employed to aid the research necessary for answering preservation and historical questions regarding the recreations yard. Since that yard was constructed on top of the historic $19^{\text {th }} \mathrm{c}$ masonry fort it was requested that we also seek the location of tunnels below the Recreation Yard and their relationship with the walls. Teams were formed to perform Non-destructive testing of concrete walls to determine the size and location of rebar, Ground Penetrating Radar for determining the location of the masonry tunnels and photogrammetry and laser scanning to provide both overall and detailed dimensional information of the current state of material decay.

\section{INTRODUCTION}

\subsection{Project}

Most preservation projects are comprised of multiple disciplines working towards a common goal. In 2012 the National Park Service with its partner in the Concrete Industry Management (CIM) program at California State University, Chico invited students and professors at Texas A\&M's Center for Heritage Conservation (CHC) to participate in creating a preservation plan for the recreation yard at Alcatraz Island. An important element of the plan was to combine multiple types of information together to aid the understanding of the analysis of current conditions recreation yard and the recommendations for its future preservation.

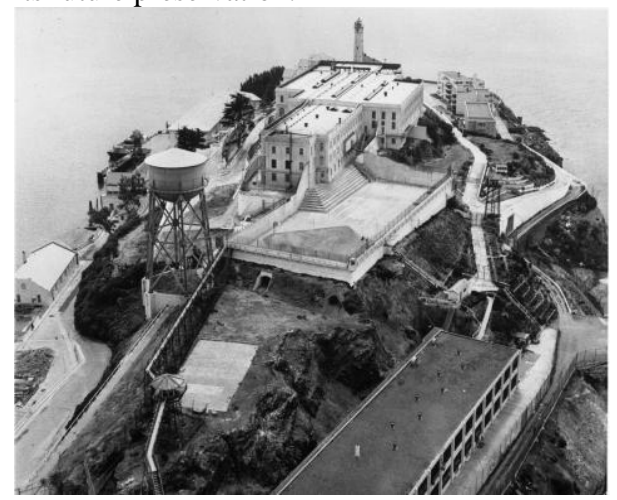

Figure 1. Alcatraz Aerial 1960s (ACLR 2010)

Alcatraz Island has a diverse history of uses that has contributed to its designation as a National Historic Landmark in 1986. The island s period of significance is identified from 1847 to 1973 when it was open to the public after being added to the newly created Golden Gate National Parks in 1972. The important historical uses of the island consist of its time as a military fort in the 1850 `s, as the site of the West Coast`s first lighthouse (since replaced by the current lighthouse), as the former maximum-security federal prison that once held recognized gangsters like $\mathrm{Al}$ Capone, and as the birthplace of the Native American "Red Power" movement (sparked by an occupation of Alcatraz from 1969 to 1971).

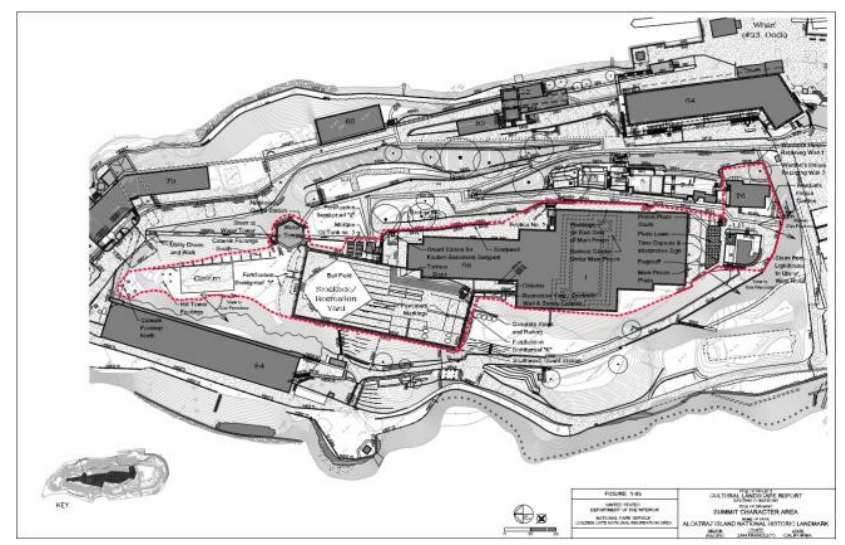

Figure 2. Stockade/ Recreation yard Drawing (ACLR 2010)

\subsection{Stockade/ Recreation Yard}

The recreation yard was constructed in 1912 to give the military prisoners some relief from the harsh conditions of prison life. Originally it consisted of reinforced concrete walls $20 \mathrm{ft}$. high surrounded by catwalks for guards and guardhouses on three corners. The unreinforced concrete floor of the yard was 
constructed on top of the civil war era batteries in 1930. On the north end of the yard soil was left uncovered by concrete creating a baseball diamond. Though changes to the recreation yard were made through periodic maintenance and security issues, the layout of the yard is much as it was nearly 80 years ago. Three primary requests were made regarding the recreation yard study: a. What is the current condition of the yard, b. What should be done to preserve the recreation yard?, c. Is it possible to confirm, through non-destructive testing (GPR), the location of the civil war era batteries.

To answer these questions three distinct but connected studies were conducted. Dr. Tanya Komas led students from The concrete Industry Management Program, from Cal State Chico to perform non-destructive testing on the rec yard walls to determine dimensional information about their thickness and any strength issues associated with cracks and wear. Dr. Mark Everett and Tim DeSmet from Texas A\&M departments of Geology and Geophysics and Anthropology respectively performed an overall Ground Penetrating Radar (GPR) study of the recreation yard floor area in an attempt to locate the Civil War era batteries. Finally, Robert Warden and the team from the $\mathrm{CHC}$ would perform visual, photogrammetric and laser scanning studies of the recreation yard walls, floor and catwalks. By pooling these three studies answers to the three questions were obtained.

\section{CONCRETE STUDIES}

\subsection{Concrete Industry Management}

The Concrete Preservation Institute (CPI) is a U.S. non-profit foundation based on a unique public/private partnership model. CPI's vision is to be the world's foremost field education and research Institute for concrete evaluation and preservation. CPI has three objectives: Education - creating hands-on, intensive learning opportunities for a diverse group of participants in a year-around field-based program; Preservation Activity (construction projects) - evaluation and preservation of historic cultural resources at Alcatraz Island and other U.S. National Park Service (NPS) sites; and Continuous Stewardship - longterm sustainability of preservation activities through on-going inspection, evaluation, maintenance, and asset management. CPI teams currently consist of undergraduate and graduate university students, such as those from California State University, Chico's Preservation Field School, and Texas A\&M University's Center for Heritage Conservation and the Geology and Geophysics Department, and will grow to include military veterans and underserved high school graduates in the future.

Work on Alcatraz Island includes adherence to strict cultural, historical, and environmental standards set forth by the U.S. Secretary of the Interior's Guidelines for the Treatment of Historic Properties, the U.S. Migratory Bird Act, and other concerns present on such sites with important cultural and natural resources. These constraints lead to interesting and often difficult logistical challenges. CPI's approach is to combine observational analysis from a collective team of experts within NPS, the concrete industry, and academia with state-of the-art materials testing and evaluation so that preservation work can be well-planned before any physical disturbance is carried out. Non-destructive evaluation (NDE) is preferred whenever possible to minimize impact and increase the potential amount of data collected. When necessary, NDE data can be correlated with data from laboratory samples obtained via careful destructive testing (e.g. drilled cores). The resulting material and structural data and analysis allows a view "inside" the concrete members that are otherwise documented with CPI's Texas A\&M partners through GPS and Laser Scanning.

CPI Non-Destructive concrete testing capabilities at Alcatraz include:

Impact Echo (IE): Used for rapid flaw detection (voids, honeycombing, and cracking damage) and thickness evaluation of concrete structural materials. The method requires access to only one side for testing. Olson Instruments' Concrete Thickness Gauge (CTG) uses the IE principle with an automatic solenoid impactor and displacement transducer (Figure 3).

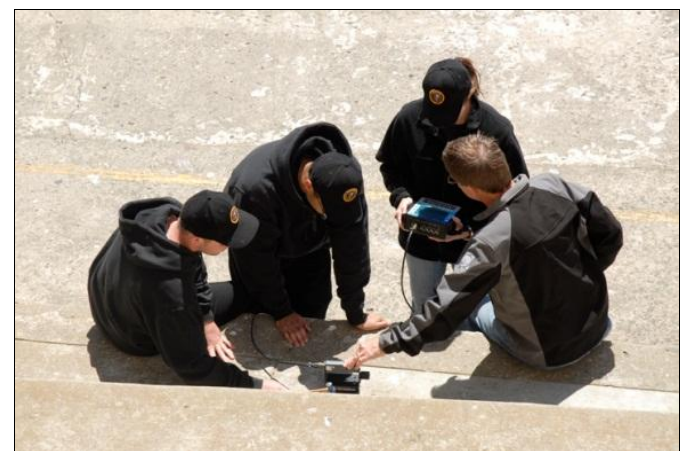

Figure 3. CSU Chico \& Texas A\&M University Students Learning to use Olson Instruments' Concrete Thickness Gauge

Spectral Analysis of Surface Waves (SASW): Used for determining concrete velocity (quality) and integrity from one side without having to know the thickness of concrete member being tested. Olson Instruments' SASW is the same base unit as the CTG (from above) with an added $20 \mathrm{~cm}$ long arm containing a second displacement transducer. The unit combines IE thickness and flaw detection with SASW velocity measurement (Figures 4 \& 5).

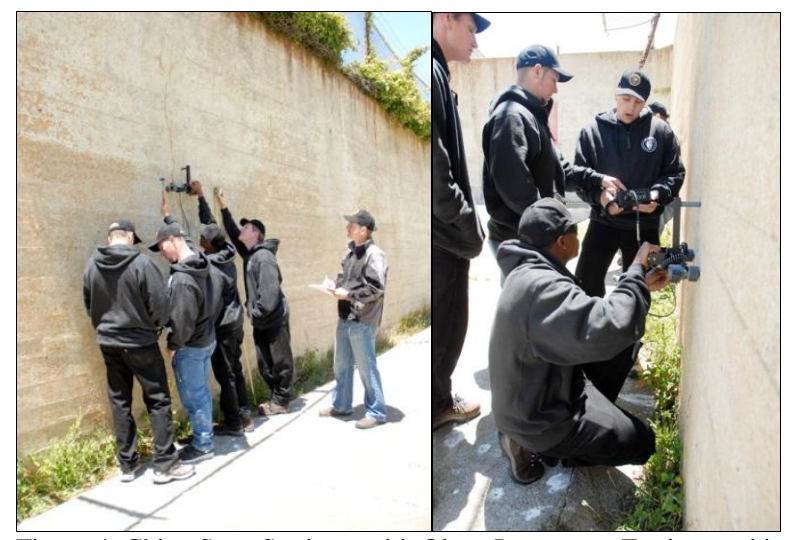

Figure 4. Chico State Students with Olson Instrument Engineer taking SASW measurements across a crack in the wall of the Rec Yard 


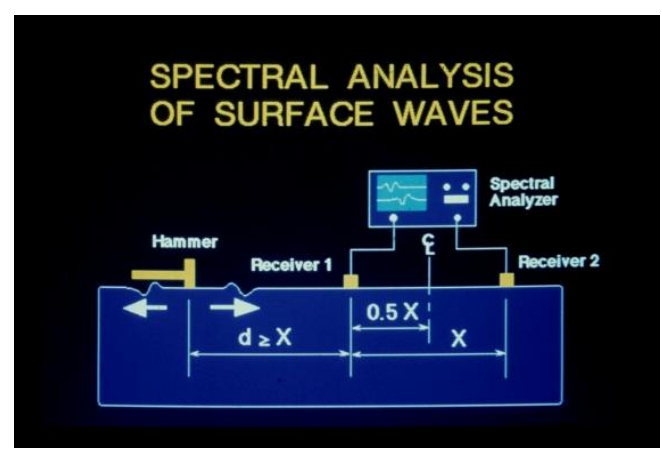

Figure 5. SASW Process (Diagram courtesy of Olson Instruments)

Ultrasonic Pulse Velocity (UPV): Measures velocity of an ultrasonic pulse through concrete to determine strength and integrity. Faster velocity typically correlates to material with greater strength and better integrity. Olson Instruments' UPV uses a $.2 \mathrm{lb}$ instrumented hammer and accelerometer for thicker material (Figures6 \& 7).

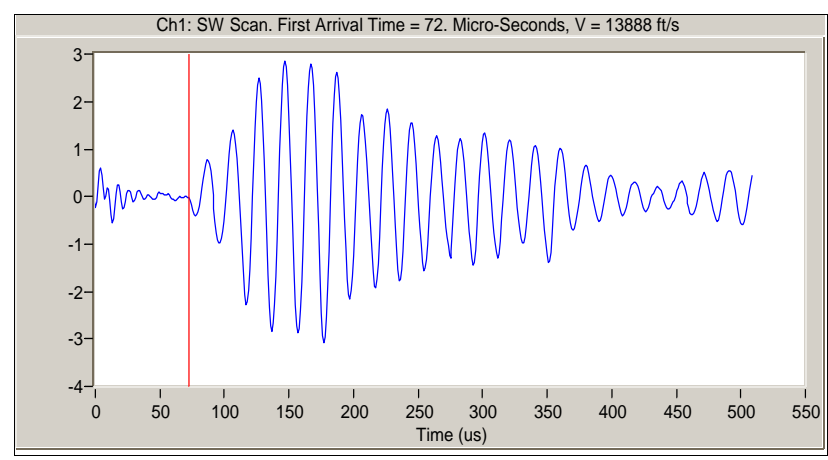

Figure 6. Sample data from UPV showing pulse travel distance of 12", compressional wave arrival time of 0.000072 seconds for a resulting velocity of $13,880 \mathrm{ft} / \mathrm{sec}$, which typically indicates good quality concrete

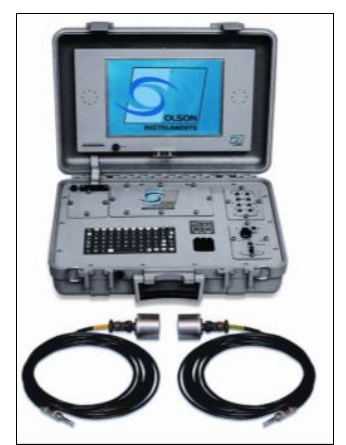

Figure 7. Olson Instruments' UPV and field ruggedized computer system

Rebar Location: Portable, quick system for detecting rebar location, direction, and diameter within concrete structures. Particularly important before core drilling for concrete evaluation, concrete removal for repair work, and determining the structural capacity of existing concrete members. The Hilti PS 200 Ferroscan is capable of individual scans over lengths of up to $30 \mathrm{~m}$, immediate viewable true images of reinforcement shown on the monitor, data transfer from scanner by infrared link for monitor viewing.

\subsection{Method}

\subsection{Ground Penetrating Radar}

The ground penetrating radar (GPR) method was selected as the most appropriate near-surface applied geophysical technique (Everett, 2013) to furnish images of the putative buried historic structures beneath the rec yard. The GPR method consists of transmitting an electromagnetic pulse into the ground and observing the reflections and scattering from buried subsurface objects. A comprehensive introduction to the GPR technique, with illustrative case studies, is provided by Jol (2009).

The GPR survey at the rec yard used the Sensors and Software PulseEkko system (www.sensoft.ca) equipped with $200 \mathrm{MHz}$ dipole antennas separated by $0.5 \mathrm{~m}$. The selection of GPR frequency and acquisition parameters is guided by site-specific resolution and penetration depth requirements. Briefly, spatial resolution is a measure of how far apart two radar reflectors must be for them to be recognized as distinct buried objects, or distinct aspects of the same buried object. The highest achievable vertical resolution is roughly one-quarter of the dominant wavelength $\lambda$ of the propagating electromagnetic signal, but in practice it cannot be better than twice the chosen time interval $\Delta t$ between each sample of the radar trace. The across-track and in-line lateral resolutions are of the same magnitude as, respectively, the chosen line spacing $\Delta L$ and chosen station spacing $\Delta x$. These are the distances between adjacent profiles and between adjacent recorded traces along a given profile. The depth of penetration $d$ is limited either by the chosen acquisition time window of the recordings, as in the present case, or by the intrinsic loss of GPR signal energy as it propagates into electrically conductive ground. The latter is the controlling factor if a sufficiently long acquisition time window is chosen. The stack number $s$ is the number of times that the pulse is repeated and the resulting traces are averaged. A higher stack number enhances the signal-to-noise ratio, since random noise is averaged out, but extends the acquisition time at each station and requires more power from the batteries. A photo of the data acquisition is shown in Figure 8, left.
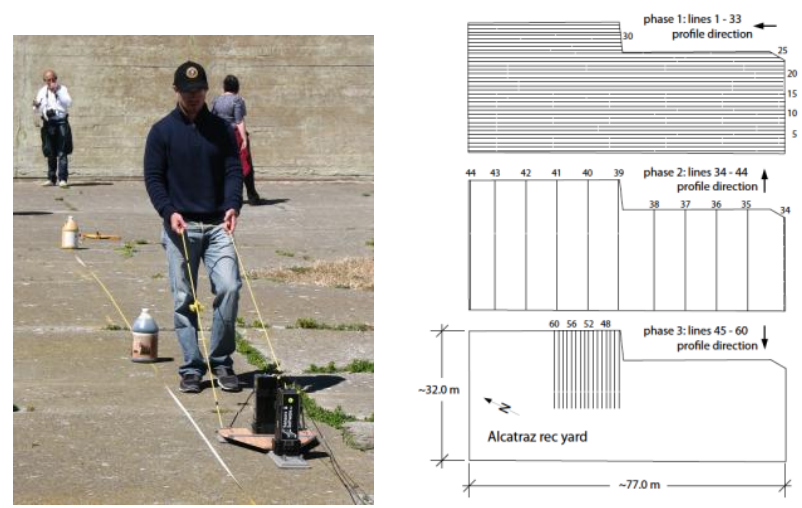

Figure 8. (left ) GPR data acquisition in cross-dipole mode; (right) GPR survey geometry.

Shown in Figure 8, right, are the three phases of GPR data acquisition. Phase 1 consisted of 33 lines directed $\mathrm{SE} \rightarrow \mathrm{NW}$ spaced $\Delta L=1.0 \mathrm{~m}$ apart and acquired along the entire length of the rec yard. Phase 2 consisted of 11 lines directed $\mathrm{SW} \rightarrow \mathrm{NE}$ spaced $\Delta L=8.0 \mathrm{~m}$ apart and acquired across the entire width of the rec yard. Phase 3 consisted of 16 shorter NE $\rightarrow$ SW lines spaced $\Delta L=1.0 \mathrm{~m}$ apart and acquired within the focus area 
shown in the figure. Data from Phases 1 and 2 were acquired in the standard in-line mode (Everett, 2013) in which both GPR antennas are centered on the profile, with the transmit antenna leading the receiver antenna, and with their long axes oriented at a right angle to the profile direction. Data from Phase 3 were acquired thrice using the in-line, a broadside, and a special cross-dipole mode; these data are not presented in this initial field report. In all cases, the station spacing is $\Delta x=0.1 \mathrm{~m}$, the sample interval $\Delta t=0.4 \mathrm{~ns}$, while the stack number is $s=4$. Assuming that the subsurface electromagnetic wave velocity is $v=0.1 \mathrm{~m} / \mathrm{ns}$, a value typical for construction fill and earthen embankments, the dominant wavelength at frequency $f=200$ $\mathrm{MHz}$ is $\lambda=v / f=0.5 \mathrm{~m}$, indicating that vertical resolution is roughly $\lambda / 4 \sim 0.1 \mathrm{~m}$. A fairly short acquisition time window was selected, $\tau=60 \mathrm{~ns}$. Recognizing that this value corresponds to the longest recordable two-way travel time for signals to propagate downward, reflect off buried objects, and return back to the surface, the maximum penetration depth $d$ is readily calculated to be $d=v \tau / 2 \sim 3.0 \mathrm{~m}$.

\subsection{Results}

It is well-known to GPR practitioners that a number of data processing steps must be performed in order to prepare GPR images for archaeological interpretation. The basic goals, strategies and procedures attending GPR data processing are summarized in Cassidy (2009). In this initial field report, we do not aim for a complete and definitive treatment of the rec-yard GPR data, but merely describe the processing steps that we performed to bring the data into presentation shape.

The first step of the GPR data processing is file reconciliation. The former is done to bring the datafiles that were actually recorded in the field into the desired survey format. For example, some of the profiles were acquired in a reversed direction or acquired out of the correct sequence. Trace editing, the second step, is a manual procedure that is done to eliminate noisy or duplicate traces, interpolate missing traces, and adjust the traces to a common time-zero datum. After that, a de-wow filter is applied. "Wow" is the ubiquitous, background variation of radar traces caused by the presence of unwanted lowfrequency interference.

A background-removal filter is then invoked that involves the subtraction, from each radar trace, of a lateral moving average of the radar amplitudes over a given early-time window. This filter mitigates the unwanted appearance of ground clutter and antenna ringing in displayed radar sections. Ground clutter is the high amplitude, laterally continuous signal seen in radar sections at early time. Ground clutter is caused by direct coupling, or cross-talk, between the TX and RX antennas and contains no useful subsurface information. The background removal filter cleans up the early portion of the radar section and permits a better visualization of very shallow reflectors. A trace equalization filter is then applied. This is similar to the background-removal filter except that it operates on the latetime portions of the traces. Its effect is to remove any residual lateral trace-to-trace variations which appear as "vertical striping" in the section.

Finally, a gain control function is applied to radar traces in order to correct for geometric spreading and attenuation of the propagating wavefront, and to equalize the signal returns from all depths. There are many different types of gain functions that could be applied. We used a simple power-law gain function to boost the strength of the late-time signals. The objective of applying such a gain function is to enable visualization of both shallower and deeper reflectors on radar sections at roughly the same display intensity.

In summary, the GPR data processing steps that we performed were:

1. data and file reconciliation

2. low-cut dewow filter

3. background subtraction filter

4. trace equalization filter

5. gain control

An example of raw and processed GPR data sections, before and after the application of the filters and gain control, is shown in Figure 9.

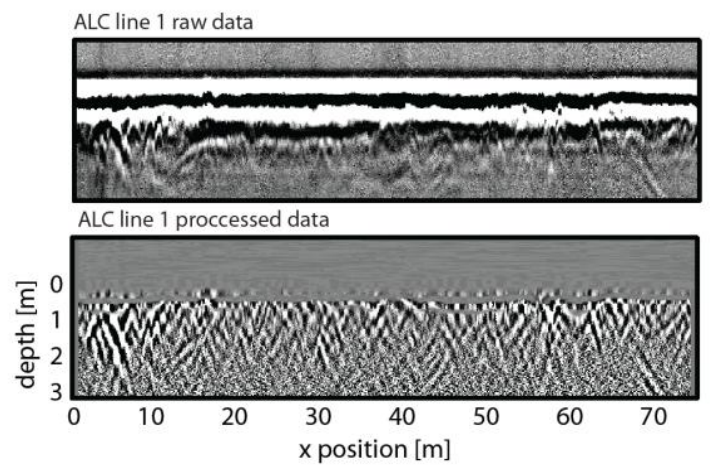

Figure 9. (top) example of raw GPR data; (bottom) after processing.

The processed GPR data from selected lines acquired during Phase 1 are shown in Figures $a \& f$. For comparison, we also show the location of each profile with respect to the present-day rec yard perimeter walls, in addition to the locations of the historic earthen fortifications, namely traverses I,J, and K.

(a)

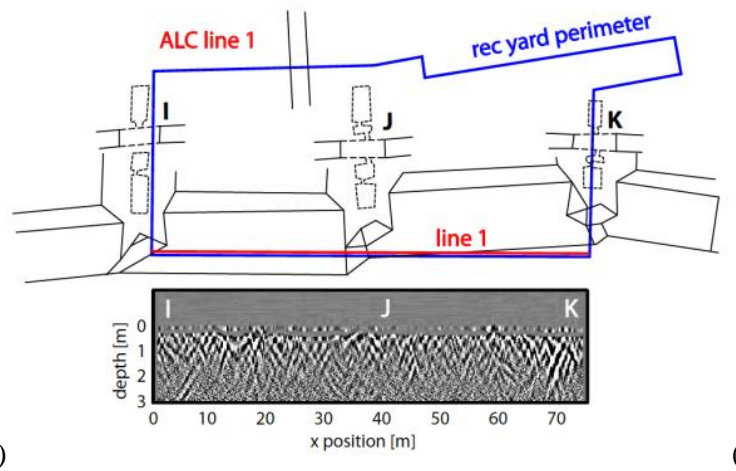

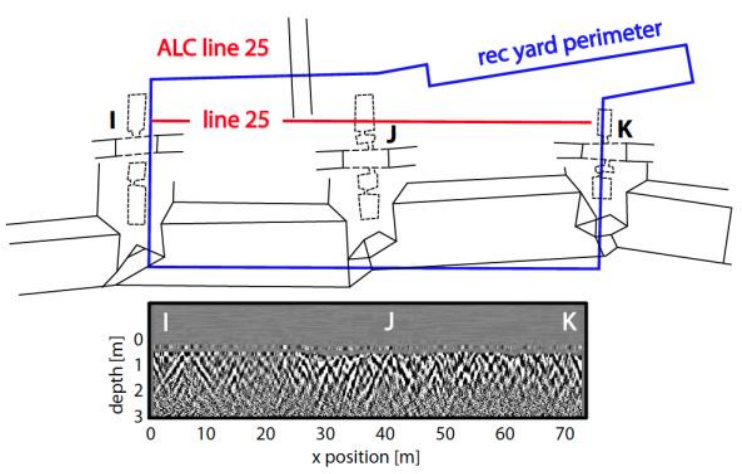

(f) 


\subsection{Discussion}

In Figure 10, from the Phase-1 and Phase-2 acquisitions respectively, are shown some of the correlations between features observed in the GPR sections and locations of the putative buried historic fortifications.

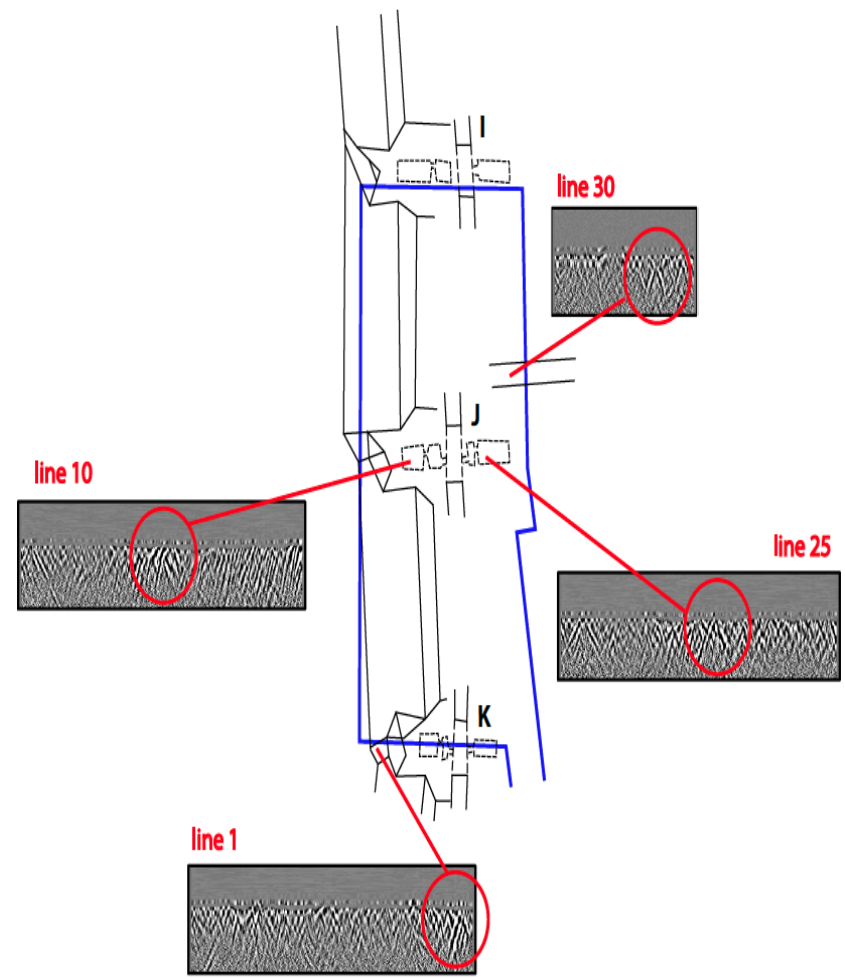

Figure 10. GPR signatures of putative historic structures, from the Phase-1 data acquisition.

\subsection{GPR Conclusions}

A GPR survey using $200 \mathrm{MHz}$ antennas, with $~ 3.0$ depth of penetration and $\sim 0.1 \mathrm{~m}$ lateral and vertical resolution, was conducted over a 5-day period in June 2012 at the rec yard at Alcatraz in order to image buried civil war-era earthen fortifications. A total of 33 profiles were acquired along the entire length of the yard and a further 11 profiles were acquired across the width. Elementary data processing steps included the application of standard filters and a gain function. The processed GPR sections show good correlations between radar reflection events and the locations of the buried fortification structures derived from historical map analysis. A 3-D data cube was constructed and two of the cut-away perspective views show that traverse $\mathrm{K}$, in particular, has a strong radar signature.

The GPR survey proved to be successful but it is likely that higher signal-to-noise and deeper penetration could have been achieved using a higher stack number and a longer acquisition window. A comparison of the obtained dataset with another one using $100 \mathrm{MHz}$ antennas would also be useful. The data processing could be enhanced by exploring different gain controls and possibly applying a migration algorithm to collapse the diffractors and dipping reflection events to their correct positions in the subsurface. Finally, the exploration of the 3-D data cube is still on-going and it would be advisable to further develop spatial filters including edge-detecting algorithms to better isolate radar events that are laterally continuous.

\section{SCANNING AND PHOTOGRAMMETRY}

\subsection{Recreation yard Floor}

The recreation yard floor was constructed some 20 years after the walls of the recreation yard but they contain important historical information to the daily life of the prisoners. From a preservation point of view it is important to understand impacts of tourism, wildlife, and climate on its integrity. To begin that understanding we performed scans of the floor from multiple positions. The scans were to serve multiple purposes such as contours that might offer information on settlement issues and location information for cracks, historical markings, and patches. An added benefit of the scans would be an ability to correlate GPR data with other surface defects.

Scans were accomplished with a Riegl z390 scanner with a Nikon D200 camera. Scans in the recreation yard were registered with other scans in the yard and around the island through control points located with a total station. Students created the survey network and performed both the scanning and the total station work. One of our goals is to use these scans as foundations for other information. (Figure 11)

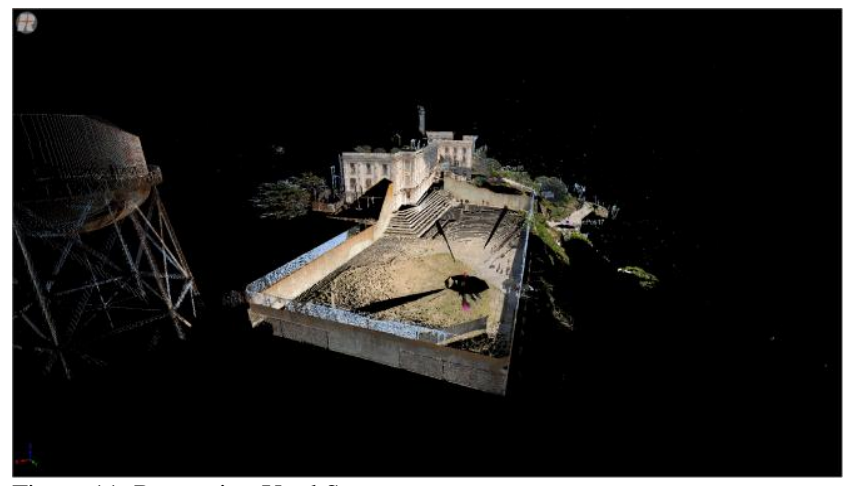

Figure 11. Recreation Yard Scan

By taking the information from the scan and aerial photographs and combining that with the GPR time slices and historical maps we begin to get a layered image of the relationship of different datasets. Figure 12

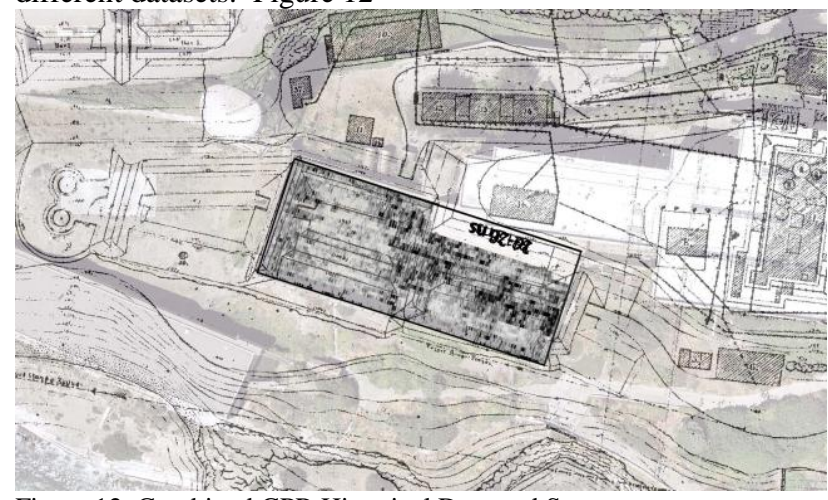

Figure 12. Combined GPR Historical Data and Scan

\subsection{Walls}

The walls were studied through photography and on site visual analysis. Photographs were taken of short sections of the wall and analysed for various kinds of wear. These photographs were inserted into AutoCad and coded for a visual explanation of the wall's condition. Later these image condition maps were registered with the scans to produce a $3 \mathrm{D}$ condition model of the walls. (Figure13.) 


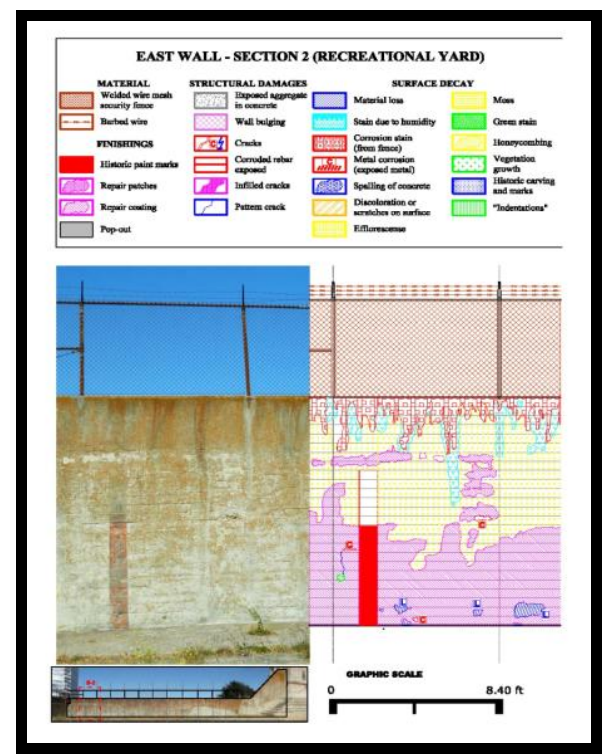

Figure 13. Wall Damage Map

\subsection{Catwalks}

The catwalks were constructed along with the wall in 1912 to serve as a way to safely watch the prisoners in the recreation yard. Guard towers were placed on the northwest, northeast, and southwest corners of the recreation yard. (Figure 14) From these locations, a guard would have views of the entire recreation yard to watch the prisoners. Chain-link fencing was added around 1943 to provide further security. (Figure 15)

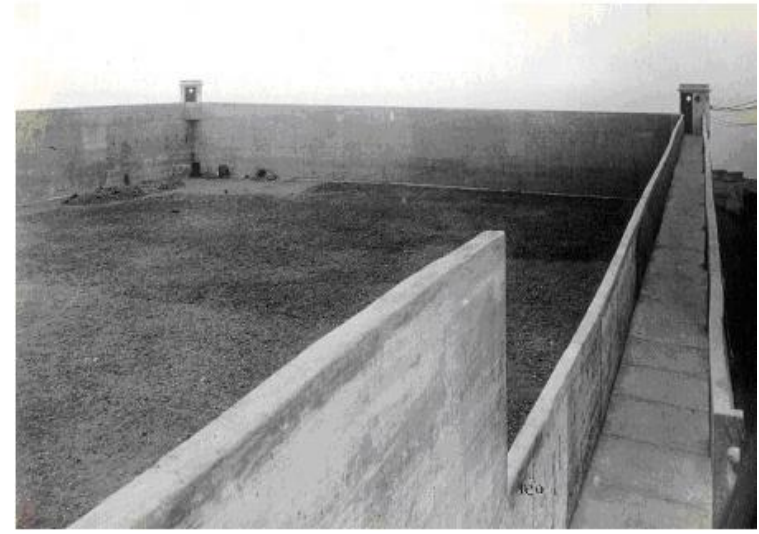

Figure 14. Recreation Yard Walls

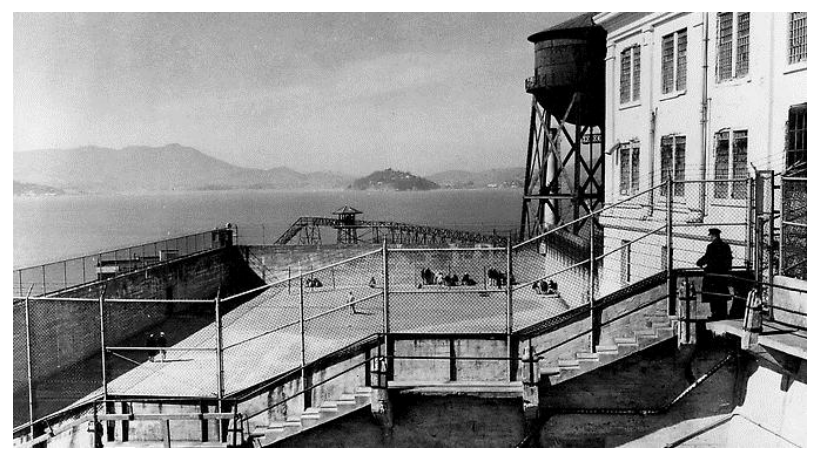

Figure 15. Recreation Yard Fencing

Over the past 40 years, the condition of the catwalks has degraded significantly. The harsh climate has caused many problems with the concrete and the rebar within the concrete.
Figure 16 shows documentation of the decay. A Combination of laser scanning and photogrammetry was used in conjunction with Autocad to demonstrate not only the qualitative but also the quantitative decay of these elements.

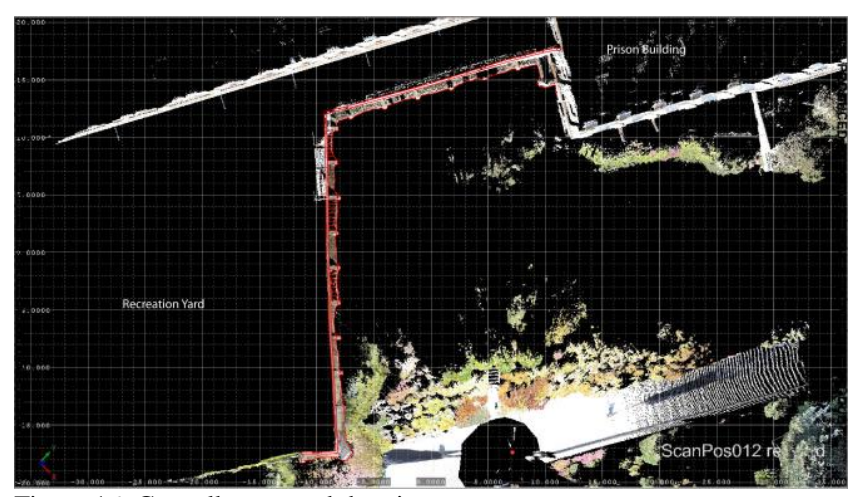

Figure 16. Catwalk scan and drawings

\section{CONCLUSIONS}

With most data gathering coming from digital instruments and in forms that are foreign to those outside of those particular disciplines it becomes beneficial to be able to visualize information in shapes and colors rather than tables of numbers. The ramifications of visual presentations in preservation can be tremendous since better understanding could lead to better decision making and more efficient funding. The GPR time slice image of the recreation yard and the early batteries is a good example. GPR data is difficult to visualize and understand unless you have some experience with how the instruments work. When overlaid onto the earlier information it becomes clearer how one can interpret it. The same is true for most of the non-destructive testing equipment used in investigating the walls. Waveforms calibrated with visual images may also lead to better interpretation of what is occurring within the walls.

As instruments progress data types will constantly be in flux so no single method of visualization will suffice. However, it does seem promising that $3 \mathrm{D}$ models in various forms will serve as foundations for displaying historical and technical information for many years to come. These methods of explaining existing conditions in concert with demonstrations of the effects of solutions derived from them will enhance the chances that those solutions will be correct.

\section{REFERENCES}

Cassidy, N.J. 2009. Ground penetrating radar data processing, modelling and analysis, in H.M. Jol (ed.), Ground penetrating radar: theory and applications, Elsevier Science, 141-176.

Everett, M.E. 2013. Near-surface Applied Geophysics, Cambridge Univ. Press, to appear April 2013.

http://www.cambridge.org/us/knowledge/isbn/item7078383

Jol, H.M. 2009. Ground-penetrating radar: Theory and Applications, Elsevier Science, 544pp.

Mundus Bishop 2010. Alcatraz Island National Historic Landmark: Cultural Landscape Report.

www.nps.gov/goga/historyculture/alcatraz-clr.htm 